\title{
Perfil metodológico de experimentos sensoriais de alimentos de 2014 a 2019
}

\author{
Amanda Felix Camocardi ${ }^{1}$, Eric Batista Ferreira ${ }^{2 *}$
}

\section{Resumo}

A análise sensorial surgiu da necessidade da melhoria da qualidade dos alimentos para além de suas características físicas, químicas e microbiológicas. Os atributos sensoriais são utilizados para acessar a qualidade sensorial de um alimento bem como o quanto este está de acordo com os desejos do consumidor. Experimentos são planejados na indústria e nos centros de pesquisa com o intuito de detectar diferenças entre formulações e preparos de alimentos com o objetivo de eleger os mais saborosos e nutritivos, e que tenham maior probabilidade de venda ou comercialização. No entanto, a literatura é escassa de estudos de revisão sobre as principais características metodológicas dos experimentos sensoriais. Este trabalho se trata de uma revisão de literatura integrativa que objetiva traçar o perfil dos experimentos sensoriais de 2014 a 2019. Em uma pesquisa de 1989 artigos, filtrada para 236 e refinada para 66, observou-se que a mediana do número de participantes foi de 50 pessoas e 10 para provadores treinados, 1 alimento ou produto analisado, 4 amostras para avaliação, 3 tratamentos e apenas 1 repetição (sessão). Os principais atributos utilizados são, cor, aroma, sabor e textura. O conhecimento das características comumente utilizadas em experimentos sensoriais pode auxiliar pesquisadores a planejar novos experimentos, ou ainda, ser alvo de críticas, para que os próximos experimentos sejam melhorados, sob algum ponto de vista.

Palavras-chave: Revisão integrativa. Análise sensorial. Bibliometria. Sensometria.

\section{Methodological profile of food sensory experiments from 2014 to 2019}

\begin{abstract}
Sensory analysis came from the need to improve food quality beyond its physical, chemical and microbiological features. Sensory attributes are used to assess the sensory quality of food as well as how well it meets the consumer's wishes. Experiments are designed in industry and research centers to detect differences between food formulations and preparations to choose the most tasty and nutritious ones, and those most likely to be sold or traded. However, the literature is scarce of review studies on the main methodological characteristics of sensory experiments. This paper is an integrative literature review that aims to profile the sensory experiments from 2014 to 2019. A survey of 1989 articles, filtered to 236 and refined to 66, found that the median number of participants was 50 people and 10 trained tasters, 1 food or product analyzed, 4 samples for evaluation, 3 treatments and only 1 replication (session). The main attributes used are color, aroma, taste and texture. Knowing the characteristics commonly used in sensory experiments can help researchers to design new experiments or criticize them so that future experiments can be improved from some point of view.
\end{abstract}

Keywords: Integrative review. Sensory analysis. Bibliometrics. Sensometrics.

${ }^{1}$ Universidade Federal de Alfenas. Alfenas, MG. Brasil.

https://orcid.org/0000-0001-5518-3674

${ }^{2}$ Universidade Federal de Alfenas. Alfenas, MG. Brasil.

https://orcid.org/0000-0003-3361-0908

*Autor para correspondência: eric.ferreira@unifal-mg.edu.br

Recebido para publicação em 02 de novembro de 2019. Aceito para publicação em 02 de fevereiro de 2020.

e-ISSN: 2447-6218 / ISSN: 2447-6218 / (c) 2009, Universidade Federal de Minas Gerais, Todos os direitos reservados. 


\section{Introdução}

A metodologia é a "arte de dirigir o espírito na investigação da verdade" ou "aplicação do método no ensino", isto é, consiste no modo de aplicar ou entender uma hipótese, tratando-se de ciência (Ferreira, 2006). A epistemologia de Kant diz que é preciso um sujeito e um objeto que, envolvidos, produzam conhecimento. O sujeito propõe-se a conhecer o objeto e o aspecto da realidade a ser conhecido, revelando a necessidade de pressupostos que norteiam toda a pesquisa (Carvalho, 2000). Dessa forma, a definição dos métodos torna-se essencial para resultados mais próximo da realidade.

A crescente complexidade de informações torna imprescindível o desenvolvimento de artifícios, no contexto da pesquisa cientificamente embasada, capazes de delimitar etapas metodológicas mais concisas e de propiciar melhor utilização das evidências elucidadas em inúmeros estudos, sendo que a revisão integrativa emerge como uma metodologia que proporciona a síntese do conhecimento e a incorporação da aplicabilidade de resultados de estudos significativos na prática (Souza, 2010; Silveira, 2005).

A análise sensorial surgiu da necessidade da melhoria da qualidade dos alimentos para além de suas características físicas, químicas e microbiológicas (Texeira, 2009). Análise sensorial é uma disciplina científica usada para evocar, medir, analisar e interpretar reações das características dos alimentos/produtos e materiais como são percebidos pelos sentidos da visão, olfato, gosto, tato e audição (ABNT, 1993). Os atributos sensoriais são utilizados para acessar a qualidade sensorial de um alimento bem como o quanto este está de acordo com os desejos do consumidor. Experimentos são planejados na indústria e nos centros de pesquisa com o intuito de detectar pequenas diferenças entre formulações e preparos de alimentos com o objetivo de eleger os mais saborosos e nutritivos, e que tenham maior probabilidade de venda ou comercialização. No entanto, a literatura é escassa de estudos de revisão sobre as principais características metodológicas dos experimentos sensoriais.

Experimentos sensoriais bem conduzidos e eficientes vão ao encontro das necessidades do consumidor, que subentende que um produto oriundo da indústria de alimentos tem as características sensoriais por ele desejadas. E, ainda, contribuindo para que as informações constatadas nas avaliações sensoriais possam servir de suporte técnico para pesquisas, indústrias, marketing e controle de qualidade do item produzido (Rossini, 2012).

Com isso, objetiva-se identificar o cenário geral de materiais e métodos usualmente utilizados em estudos de análise sensorial nos anos de 2014 a 2019 a partir de um levantamento bibliográfico. A justificativa baseia-se na demanda percebida a partir da realização de estudos de estatística computacional em Sensometria, onde é necessário estabelecer um limiar entre o que é factível na prática e o que é uma abstração computacional, no tocante ao número de consumidores, provadores treinados, alimentos/produtos, tratamentos, repetições e sessões. Além disso, entende-se que o conhecimento do perfil metodológico de experimentos sensoriais pode servir de respaldo para novas pesquisas nesta área.

\section{Material e métodos}

O presente trabalho se trata de uma revisão de literatura integrativa, que é uma das estratégias para identificar as evidências existentes para se estabelecer um cenário, fundamentando as tendências em pesquisa que envolvem análise sensorial, estatística e desenvolvimento de novos produtos (Beyea; Nicoll, 1998).

Para elaboração dessa revisão foram seguidas as etapas do Manual de Revisão Bibliográfica Sistemática Integrativa (2014), com adaptações necessárias ao objetivo proposto. Como recomendado pelos autores, partiu-se de uma etapa preliminar denominada como zero, onde se cultivou o espírito investigativo. Considerou-se aqui o pensar sobre possíveis perguntas que se fariam a partir do problema em questão. Sendo assim, é preciso investigar o que se deseja conhecer e, ainda, dominar as informações e desenvolver habilidades de síntese para análise crítica das evidências encontradas (Pereira; Bachion, 2006). Portanto, essa fase é o preâmbulo para uma revisão integrativa de sucesso. Neste contexto, definiu-se a importância de registrar quali-quantitativamente os achados metodológicos em análise sensorial para orientação e guia de estudos futuros.

Na primeira etapa, trata-se da identificação do tema e seleção da questão de pesquisa, onde objetivou-se também formular uma hipótese ou questão de pesquisa que apresentasse relevância (Polit; Beck, 2006), levando em consideração a sigla PICOT: $(P)$ significa considerar a população alvo: pesquisadores da área; $(I)$ considerar o interesse da intervenção ou a área de interesse: fornecer informações metodológicas que sirvam de recomendação em estudos de análise sensorial; $(C)$ comparar tipos de intervenção ou grupos: obter os mais variados materiais e métodos aplicados neste tipo de avaliação; $(O)$ obter resultados e considerar os efeitos a serem alcançados com a intervenção: concluir sobre um possível perfil ou, pelo menos, tendência encontrada na literatura; $(T)$ considerar o tempo do estudo: foram analisadas publicações dos últimos cinco anos.

O formato PICOT, em geral, fornecem uma estrutura eficiente para a busca de dados em bases eletrônicas (Stillwell, 2010), então tomou-se como pergunta norteadora: Em análise sensorial, é possível identificar um perfil de materiais e métodos quando comparam-se os estudos dos últimos cinco anos? Além disso, definiram-se os descritores, em inglês e português para a busca, sendo: "análise sensorial" e "sensorial/sensory analysis" em que foi 
considerado o artigo que contemplasse pelo menos uma das palavras, ou seja, que apresentasse no título, resumo ou palavras-chave qualquer uma das palavras dos descritores, juntas na frase ou não. Foram escolhidos somente dois, pois demais descritores gerariam um número de artigos muito denso para o estudo em questão, mas que não deixam de ser importantes para pesquisas futuras. A partir daí foi possível listar os artigos encontrados pelo conjunto de operadores utilizados.

A segunda etapa procurou melhorar a evidência utilizada. Portanto, para seleção dos textos foi feito um levantamento na base de dados do Google Acadêmico, a partir do uso do programa Publish or Perish - POP (Harzing, 2007) e fontes primárias tais como o Caderno de Ciências Agrárias da UFMG. Também, para acesso de algumas publicações, fez-se uso do portal de periódicos CAPES (www.periodicos.capes.gov.br).

Então, a partir dos resultados para os descritores, em português, "análise sensorial", e inglês, "sensorial/ sensory analysis", foram encontrados e registrados pelo 'POP' cerca de 1.978 artigos, enquanto que no Caderno de Ciências Agrárias da UFMG foram 11 artigos revisados, totalizando 1.989 artigos.

Devido à elevada correspondência encontrada a partir dos descritores, definiu-se os critérios de inclusão e exclusão (De-La-Torre-Ugarte-Guanilo, 2011). Sendo uma revisão integrativa quali-quantitativa, considerou-se incluir artigos que apresentassem de forma clara e objetiva as etapas metodológicas para avaliar o produto em análise, incluindo valores numéricos. A terceira etapa teve como objetivo, portanto, avaliar criticamente as evidências dos estudos pré selecionados e selecionados. Após selecionados os artigos originais, avaliou-se quanto aos critérios de inclusão e exclusão e procedimentos de validade, para determinar quais eram os mais relevantes, válidos, confiáveis e aplicáveis à questão em estudo.

Foram selecionados aqueles que continham informações acerca do número de consumidores usuais ou provadores treinados, alimentos ou produtos avaliados, presença de algum tratamento no alimento ou produto (como mudanças químicas ou físicas), número de repetições na aplicação da análise sensorial e ferramenta de análise sensorial (teste de aceitação, preferência, etc.), além de ter sido publicado de 2014 à 2019. Foram excluídos os artigos que não abrangeram, em essência, os critérios estabelecidos acima e também aqueles que apresentaram os dados e análises de forma incompleta, que não possuíam no título, resumo ou palavras-chave os descritores estabelecidos e aqueles que não pertenciam às bases de dados exploradas. Dos 1.989 artigos encontrados, foram lidos 236 resumos, palavras-chave e título das publicações. Em seguida, organizaram-se os artigos selecionados. No entanto, cada tipo de pesquisa tem suas vantagens e limitações, tornando-se, fundamental saber até onde se podem aplicar os resultados de cada uma delas (Oliveira, 2014).

Já na quarta etapa, integraram-se as evidências, isto é, das 256 publicações, considerou-se, ainda, que as publicações tivessem pelo menos 10 citações - para os artigos encontrados no descritor em português "análise sensorial" - e no mínimo 30 citações - para os que corresponderam ao descritor em inglês "sensorial/sensory analysis" - pois inclui trabalhos do mundo todo e possuem maior correspondência na literatura. Considerou-se as citações, pois foi de interesse dos autores, neste estudo, identificar os materiais e métodos dos estudos maior impacto em análise sensorial. Tal critério não foi utilizado quando se tratou dos artigos encontrados no Caderno de Ciências Agrárias.

Com isso, formou-se uma biblioteca individual com os 66 artigos selecionados (Apêndice 2), analisaram-se as informações usando os critérios de validação supracitados e categorizaram-se os conteúdos analisados e respondentes à pergunta de pesquisa. Na quinta etapa, fez-se a discussão dos resultados e na sexta e última etapa fez-se a apresentação da síntese do conhecimento produzido.

As análises estatísticas foram realizadas no software R versão 3.6.1 (R Core Team, 2019), principalmente por meio dos pacotes asbio (Aho, 2019) e graphics (R Core Team, 2019). Foram estimadas medianas por ponto e por intervalo, construídos boxplots e calculadas frequências percentuais de variáveis categóricas, como a classe alimentar que era foco do estudo revisado.

O intervalo com $95 \%$ de confiança para a mediana foi calculado pela expressão

$$
\begin{gathered}
L I=\frac{n}{2}-\frac{1,96 \sqrt{n}}{2} \text { ésimo valor } \\
L S=1+\frac{n}{2}-\frac{1,96 \sqrt{n}}{2} \text { ésimo valor }
\end{gathered}
$$

em que $n$ é o tamanho da amostra, 1,96 é o quantil superior de 2,5\% da normal padrão e os limites superior e inferior são dados pelo valor estiver na posição indicação pelo cálculo.

\section{Resultados e discussão}

Segundo as etapas da revisão integrativa descritas na Metodologia, um conjunto inicial de 1.989 artigos (1.978 retornados pelo POP e 11 artigos da revista Caderno de Ciências Agrárias) foram obtidos, filtrados para 236 e refinados para 66 (Apêndice 2) que se enquadravam em todos os descritores estabelecidos neste trabalho (Figura $1)$. 
Figura 1 - Infográfico contendo as etapas da revisão integrativa e o número de artigos obtidos em cada etapa

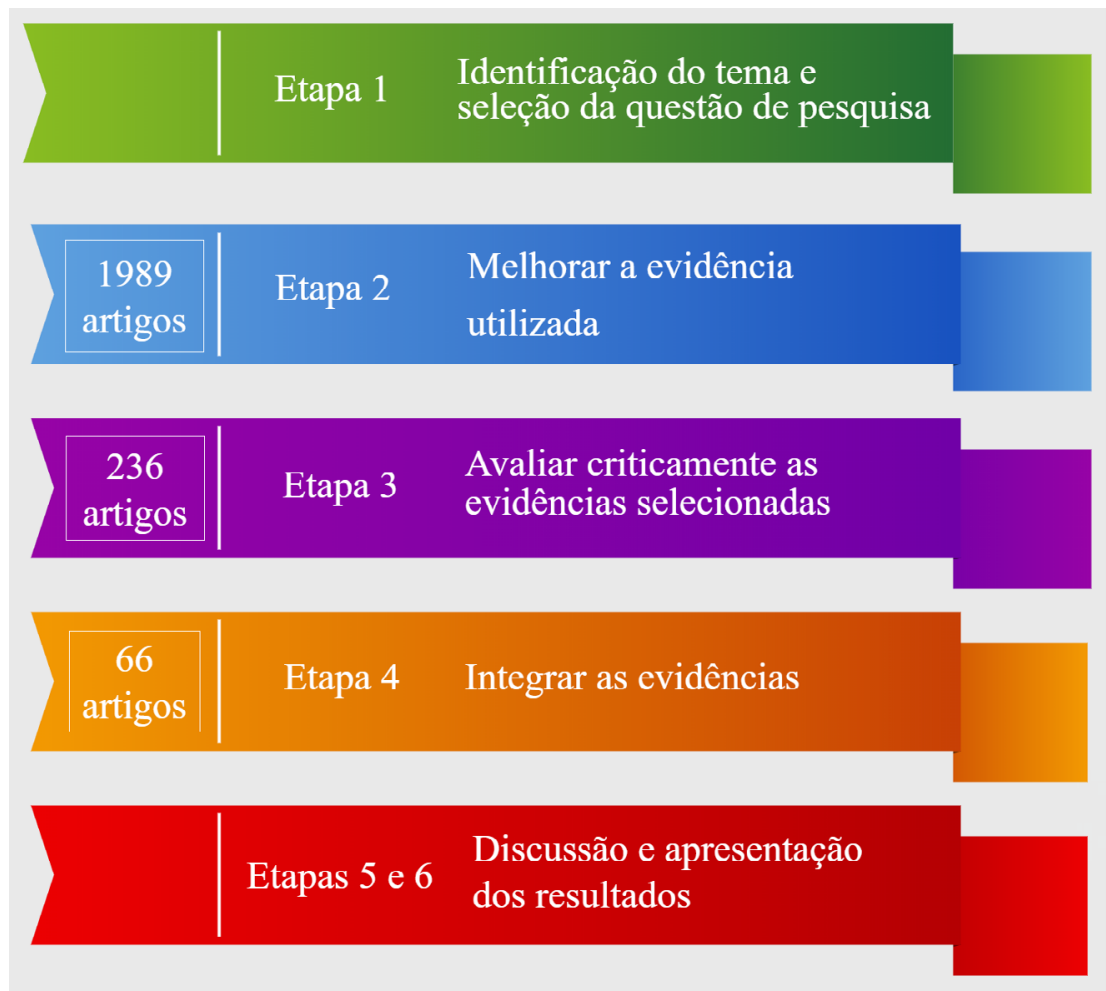

Partindo dos objetivos propostos, procurou-se traçar um perfil (Apêndice 1) de algumas características normalmente encontradas em estudos de análise senso- rial, na Tabela 1 encontram-se os dados quantitativos identificados.

Tabela 1 - Principais características metodológicas dos artigos consultados e suas estatísticas: mediana, intervalo com 95\% de confiança para a mediana, valor mínimo, máximo e boxplot

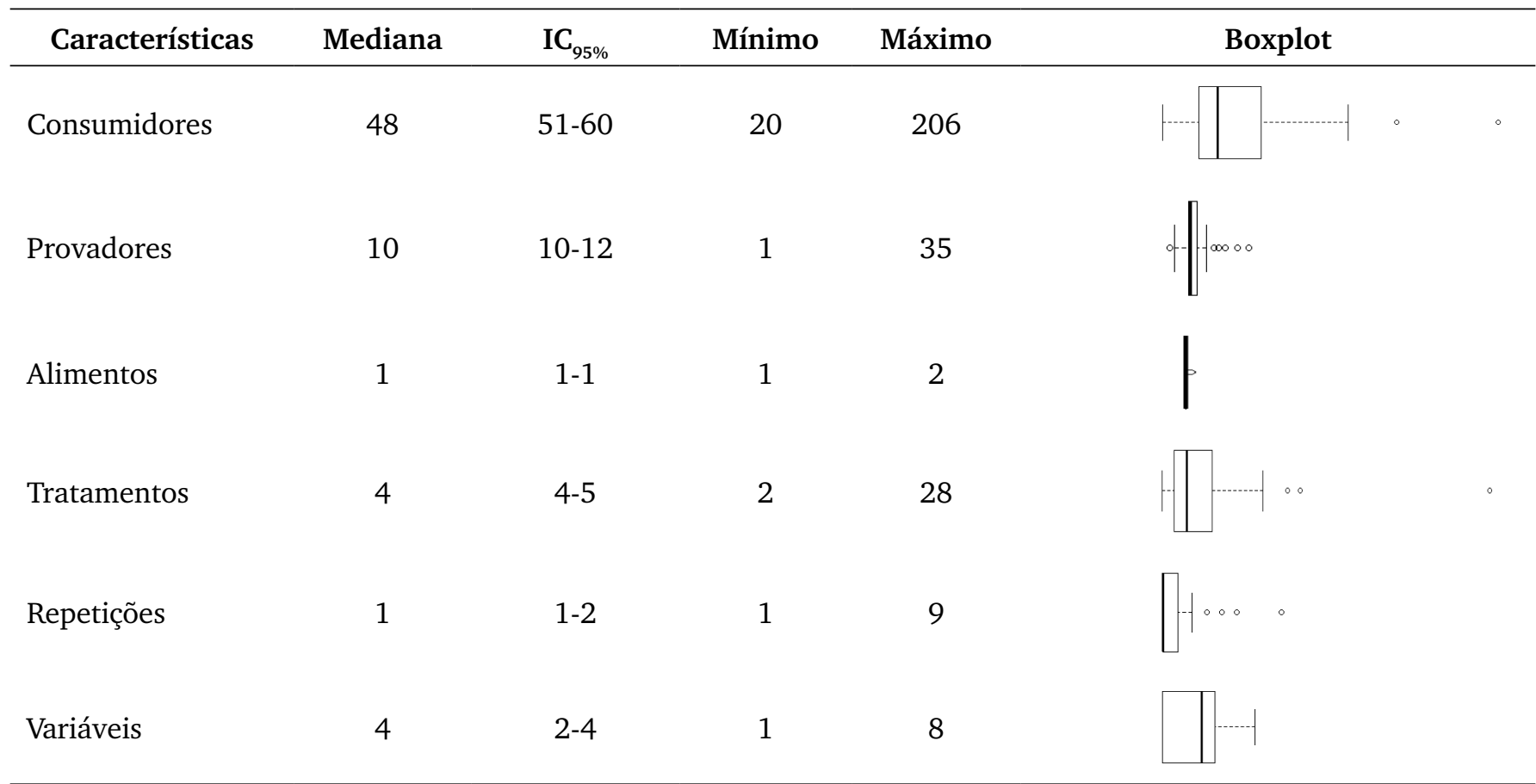

Com relação ao número de sujeitos envolvidos nos experimentos, os resultados evidenciam características esperadas. O elevado número de consumidores (variando de 20 a 206, mas concentrados de 43 a 60) se justifica pela alta variância das notas dadas por esses sujeitos e, ainda, pode-se observar no boxplot que há uma dispersão considerável dos dados, caracterizando a variação com que estudos com consumidores podem apresentar em função do tipo de análise. Nesta revisão, por exemplo, o mínimo encontrado (20 consumidores) tratou-se de uma 
sensorial de café acrescido de antioxidante (Martinez-Saez, 2014) e o máximo encontrado (206 consumidores) de uma sensorial de pães e bolos com adição de chia na receita (Fernandes; Salas Mellado, 2017), o que denota a dificuldade de se estabelecer um perfil do número de consumidores ideal a ser utilizado.

Como o julgamento dos consumidores apresenta elevada variância, o tamanho da amostra precisa ser grande para que sejam estimados os parâmetros de interesse, como médias e proporções. Em geral, estudos com consumidores se referem basicamente a testes afetivos, ou seja, deseja-se saber o quanto o consumidor gostou de cada formulação, qual ele prefere ou ainda qual ele compraria. Como preferência e aceitação variam muito de consumidor para consumidor, são coletadas as maiores amostras que o pesquisador tem condições de coletar.

Por sua vez, o número de provadores treinados é de ordem de grandeza bem menor, afinal, passam por fases de recrutamento, seleção e treinamento, que em geral são caras e demoradas. Além disso, é comum que os provadores sejam voluntários. Pesquisadores de vários países podem oferecer um pagamento pela participação, mas no Brasil isso não é permitido, ainda que atendam às sessões, tenham disponibilidade e assiduidade. Portanto, usualmente, são poucos participantes. Após o treinamento, esses sujeitos passam a ser como "instrumentos calibrados" para pontuar a intensidade de atributos sensoriais, como ponto de torra, fragrância, aroma, corpo, acidez e amargor avaliados em blends de café (Ribeiro, 2014).

Devido a seu treinamento, os provadores apresentam baixa variância, além de suas preferências e predileções ficarem de fora na hora do julgamento. Sendo assim, o tamanho do painel (da amostra) pode ser pequeno sem perda de precisão para o experimento. Na Tabela 1 pode-se observar que existem estudos que contemplam apenas um provador treinado, considerado expert, no caso, um degustador que realizou prova de xícara para classificar o café analisado (Lima, 2008). Provadores treinados participam, em geral, de experimentos descritivos e discriminativos, ou seja, que têm objetivo de descrever sensorialmente um alimento ou comparar diferentes preparos ou formulações.

Dos artigos analisados, aproximadamente $52 \%$ (32) envolviam análise sensorial com consumidores e $46 \%$ (30) com provadores treinados. Apenas três artigos caracterizaram e avaliaram a aceitação do alimento através de provadores treinados e consumidores simultaneamente (Lievore, 2015; Bemfeito, 2016; Duarte, 2018).

Quanto ao número de alimentos analisados nos estudos, o mais comum é a escolha de apenas um alimento onde fez-se adição de um componente ou aprimoramento de sua tecnologia de fabricação. Observa-se pelo boxplot que essa categoria apresenta menor dispersão. Em geral são feitos testes de aceitação para verificar o impacto da concentração de determinado insumo, para comparar tratamentos diferentes ou mesmo verificar sua intenção de compra. Os tratamentos utilizados os experimentos dependem, normalmente, do número de formulações e repetições analisadas e, ainda, da procedência do alimento, como no caso de vinhos e cafés, que podem ter diversas regiões de origem.

Para a formulação, considera-se todo tipo de alteração que o alimento ou produto sofreu para então ser avaliado. Então, se um bolo é acrescido de farinha de semente de abóbora em três concentrações diferentes, consideram-se três formulações (tratamentos). As repetições representam a quantidade de vezes que aquele mesmo alimento é avaliado (Bitencourt, 2014).

Vale ressaltar que, por vezes, os tratamentos são obtidos pela combinação fatorial dos níveis dos fatores. Se o pesquisador decide investigar a ação do tempo sobre seis cultivares de morango, por exemplo, se procura avaliar as características em duas épocas do ano, consideram-se $2 \times 6=12$ tratamentos. Se houve 5 repetições, resultam trinta avaliações por ciclo, totalizando sessenta parcelas (Antunes, 2014).

Ainda, considerou-se o número de atributos utilizadas nos artigos para demonstrar quais delas eram mais comuns de serem encontradas, tantos em testes afetivos como descritivos. Destaca-se que para aparência foi considerado as nomenclaturas que tratavam dos aspectos visuais avaliados (aspecto geral, fase visual, etc.) e, para impressão global considerou-se nomenclaturas como aceitação global, aceitação total, teste de aceitação, entre outras que tratavam da amostra como um todo, considerando os aspectos sensoriais de uma forma geral. Como revela a Tabela 2, pode-se perceber que o principal atributo sensorial avaliado é o sabor, seguido pelo aroma e impressão global, podendo ser justificado pelo fato de boa parte dos estudos incluírem avaliação de bebidas, onde se considera, principalmente o sabor e o aroma. Além disso, a impressão global normalmente é uma forma fácil e rápida de se avaliar um alimento ou produto pontualmente, isto é, com consumidores usuais aleatórios.

Os atributos sensoriais afetivos, como cor, sabor, aroma, textura, aspecto geral e aceitação global são geralmente avaliadas em escala hedônica de 9 pontos (66,6\%), variando de 'desgostei extremamente' (1) a 'gostei extremamente' (9), e pontuadas por consumidores. Enquanto que a intenção de compra geralmente é avaliada por escala hedônica de 5 pontos $(61,5 \%)$. Por outro lado, atributos sensoriais de intensidade, como aroma frutado ou amadeirado, gosto ácido ou sabor de caramelo em vinhos (Vilela, 2015) são comumente pontuadas em escalas não estruturadas de $9 \mathrm{~cm}$ (cerca 42,8\% dos estudos analisados), por provadores treinados. Considerando o exposto, ressalta-se aspectos que podem influir sobre a análise e que não foram capazes de ser mensurados, como: o local de realização do teste; que deve ser um ambiente tranquilo, neutro, sem distrações 
Camocardi, A. F.; Ferreira, E. B.

ou interrupções, de fácil acesso, longe do processamento das amostras, sem contaminação de odores ou ruídos, além de prover conforto físico aos provadores. Também, horário e duração dos testes, sendo recomendado que não ocorram próximos aos horários das grandes refeições. Geralmente entre 10 e 11 horas da manhã e entre 15 e 16 horas da tarde são os melhores horários no Brasil. $\mathrm{O}$ teste deve durar, no máximo, 20 minutos a fim de evitar cansaço e desmotivação do provador, e é importante ofertar algum líquido (normalmente, água) para enxágue bucal para minimizar a fadiga sensorial (Minim, 2013).

Tabela 2 - Principais atributos utilizados nos estudos analisados para avaliação sensorial

\begin{tabular}{lc}
\hline Atributos mais comuns & $\%$ \\
\hline Sabor & 16,7 \\
Aroma & 14,6 \\
Impressão global & 14,6 \\
Cor & 12,9 \\
Textura & 9,9 \\
Aparência & 7,3 \\
Escala de atributos & 4,3 \\
Outros & 19,7 \\
\hline
\end{tabular}

A condução do teste deve ser inteiramente orientada pelo responsável, evitando-se falhas no procedimento (Minim, 2013). Sendo assim, o pesquisador deve ter, acima das condições supracitadas, entendimento e conhecimento da técnica a ser aplicada, além do ambiente e treinamento adequado dos provadores.

A Tabela 3 apresenta a distribuição percentual da frequência de estudos sensoriais feitos com as mais diversas classes de alimentos. Pode-se notar que é muito mais comum haver experimentos sensoriais desenvolvidos com produtos cárneos, doces, biscoitos, barras de cereais, massas, pães, bolos e cereais do que com frutas, hortaliças e legumes. Tal fato se deve ao interesse, majoritariamente da indústria de alimentos, em avaliar a aceitação de produtos ultraprocessados, com fins comerciais. Outra justificativa considerada é a dificuldade de manipulação e a falta de padronização de alimentos in natura, que podem dificultar seu emprego de um experimento sensorial. Além disso, as bebidas correspondem a 21,2\% dos estudos, sendo a segunda classe mais frequente, e se distribuindo na mesma proporção entre estudos de bebidas alcoólicas e não alcoólicas. É mais comum o uso de vinhos e cafés $(15,2 \%)$ que têm seu uso relacionado à interesses econômicos associados ao consumo.
Tabela 3 - Distribuição percentual da frequência de estudos sensoriais sobre as mais diversas classes de alimentos

\begin{tabular}{lc}
\hline Classe alimentar & $\%$ \\
\hline Cárneos e ovos & 25,8 \\
Doces/Biscoitos/Barra de cereais & 18,2 \\
Massas/Grãos/Pães/Bolos & 13,6 \\
Bebidas alcoólicas & 10,6 \\
Bebidas não alcoólicas & 10,6 \\
Hortaliças e legumes & 9,1 \\
Lácteos & 6,1 \\
Frutas & 4,5 \\
Óleos e gorduras & 1,5 \\
\hline
\end{tabular}

Outra questão investigada foi o emprego de testes estatísticos na análise de dados sensoriais. Essa informação é muito relevante para a área da Sensometria, que se trata da Estatística aplicada à Análise sensorial de alimentos. A Tabela 4 traz a frequência relativa de utilização de cada tipo de teste encontrado na revisão integrativa. Pode-se notar que a análise de variância (ANOVA), que é simplesmente uma representação tabular do teste $\mathrm{F}$ que considera a estrutura experimental de delineamento e arranjo dos tratamentos, é o mais frequente na literatura. Em seguida, apresenta-se o teste de Tukey, que comumente é empregado após a análise de variância, para tratamentos qualitativos.

Nesse momento vale ressaltar que o emprego da análise de variância para dados hedônicos (escores) é questionável, uma vez que a variável ordinal não garante o atendimento aos pressupostos desse teste. Nesse caso, testes não paramétricos equivalentes podem ser utilizados, mas essa discussão quase nunca é encontrada nos artigos da área sensorial.

Chama ainda a atenção o baixo uso de regressão (possivelmente pelo pequeno número de tratamentos quantitativos ou ainda pelo baixo número de níveis dos mesmos) e dos mapas de preferência interno e externo, que são ferramentas poderosas na investigação das razões da aceitação e intenção de compra (Minim, 2013). É interessante ressaltar que não há, nos artigos de forma geral, uma explicação sobre a escolha do teste estatístico utilizado e nem como fora feita sua aplicação, portanto, aponta-se a necessidade de que os estudos ampliem essa informação para que se justifique o uso correto da análise. 
Tabela 4 - Distribuição percentual da utilização de testes estatísticos na análise de dados sensoriais

\begin{tabular}{lc}
\hline Análise Estatística & $\%$ \\
\hline ANOVA & 40,7 \\
Teste de Tukey & 29,6 \\
Regressão & 4,9 \\
Teste t de Student & 3,7 \\
MIP (Mapa de preferências interno) & 2,5 \\
Teste F & 2,5 \\
Teste de Duncan & 2,5 \\
Outros & 11,1 \\
Não informado & 2,5 \\
\hline
\end{tabular}

Por fim, é importante salientar que este é um estudo preliminar de revisão para problematizar as premissas que orientam à análise sensorial e, também, questionar quanto à padronização do método a fim de traçar um perfil que sirva como delineamento a partir de referências já existentes, no entanto, são necessários estudos com maior aprofundamento e domínio do tema.

\section{Considerações finais}

Identificou-se, após o levantamento e seleção dos artigos que, existem tendências ao utilizar-se de estudos de análise sensorial, sendo eles: aspectos em relação à amostra que permeiam todas as esferas sensoriais a serem consideradas, como usualmente utilizam-se o cor, sabor, aparência, aroma/odor, textura e aspecto geral do alimento/produto. Além disso, deve-se optar pela análise que melhor representa o objetivo da pesquisa, isto é, adequar a avaliação de acordo com o público, consi- derando os impactos que ser um consumidor ou não do produto em estudo podem ter ou, ainda, se é necessário treinar provadores para delinear ou definir atributos e descritores para aprovação de um produto no mercado. O tipo de teste e a estatística a serem aplicados preveem o número amostral a ser considerado e antes de iniciar o estudo se faz necessário defini-los.

Com isso, pode-se concluir que para estudos em análise sensorial não há um padrão metodológico estabelecidos, mas existem recomendações para produtos ou testes associados. Por exemplo, quando se deseja adicionar um elemento/ingrediente à um produto pronto, é preciso que este seja apresentado ao provador em mais de uma concentração, além do produto isento de tal adição, para que a avaliação sensorial possa ser efetiva e para que o provador possa estabelecer parâmetros e comparações para se conhecer a melhor amostra. Por fim, é preciso que o responsável tenha embasamento, a partir de estudos anteriores ou ciência em análises sensoriais, para que sua pesquisa seja adequada e idônea.

Pode-se considerar que o perfil dos experimentos sensoriais dos últimos 5 anos é o estudo de um único alimento ou bebida, utilizando-se 50 consumidores, 10 provadores treinados, comparando-se 4 tratamentos, em uma única sessão, comumente usando alimentos cárneos, doces/ biscoitos/barras de cereias e bebidas (alcoólicas ou não). Sendo os dados analisados via análise de variância seguida por teste de Tukey a $5 \%$ de significância.

\section{Agradecimentos}

Ao professor Eric Batista Ferreira do Instituto de Ciências Exatas da Universidade Federal de Alfenas (UNIFAL/MG) por todo apoio e parceria durante a elaboração deste artigo. Ainda, à UNIFAL por permitir que a iniciação científica realizada no ano de 2018-2019 me incentivasse a aprofundar o conteúdo aqui presente.

\section{Referências}

Aho, K. Asbio: a collection of statistical tools for biologists. 2019. R package version 1.5-5.

Antunes, M. C.; Cuquel, F. L.; Zawadneak, M. A. C.; Mogor, A. F.; Resende, J. T. V. 2014. Ostharvest quality of strawberry produced during two consecutive seasons. Horticultura Brasileira 32: 168-173. Doi: http://dx.doi.org/10.1590/S0102-05362014000200008.

Associação Brasileira de Normas Técnicas - ABNT. 1993. Análise sensorial dos alimentos e bebidas: terminologia. NBR 12806. 8 p.

Bemfeito, R. M.; Rodrigues, J. F.; Silva, J. G.; Abreu, L. R. 2016. Temporal dominance of sensations sensory profile and drivers of liking of artisanal Minas cheese produced in the region of Serra da Canastra, Brazil. Jornal of. Dairy Science, 99: 7886-7897. Doi: 10.3168/jds.2016-11056.

Beyea, S.; Nicoll, L.H. Writing an integrative review. 1998. AORN J., 67: 877-80. Doi: 10.1016/s0001-2092(06)62653-7.
Bitencourt, C.; Dutra, F. L. G; Pinto, V. Z.; Helbig, E.; Borges, L. R. 2014. Elaboração de bolos enriquecidos com semente de abóbora: avaliação química, física e sensorial. B. CEPPA, 32: 19-32. Doi: http://dx.doi. org/10.5380/cep.v32i1.36927.

Carvalho, A. M.; Moreno, E.; Bonatto, F. R. O; Silva, I. P. Aprendendo Metodologia Científica. 2000. São Paulo: O Nome da Rosa. v.1.

De-La-Torre-Ugarte-Guanilo, M. C.; Takahashi, R. F.; Bertolozzi, M. R. 2011. Revisão sistemática: noções gerais. Revista da Escola de Enfermagem da USP, 45:1255-1261. Doi: http://dx.doi.org/10.1590/ S0080-62342011000500033.

Duarte, A. L. A.; Rosário, D. K. A.; Oliveira, S. B. S.; Souza, H. L. S.; Carvalho, R. V.; Carneiro, J. C. S.; Silva, P. I.; Bernardes, P. C. 2018. Ultrasound improves antimicrobial effect of sodium dichloroisocyanurate to reduce Salmonella Typhimurium on purple cabbage. International Journal of Food Microbiology, 269: 12-18. Doi: https://doi. org/10.1016/j.ijfoodmicro.2018.01.007. 
Fernandes, S. S.; Salas-Mellado, M. M. 2017. Addition of chia seed mucilage for reduction of fat content in bread and cakes. Food Chemistry, 227: 237-244. Doi: http://dx.doi.org/10.1016/j.foodchem.2017.01.075.

Ferreira, A. B. H. 2006. Dicionário da língua portuguesa. Rio de Janeiro: IBGE, 86 p. 1v. il. ISBN 978-85-240-4074-0.

Grupo Anima Educação. 2014. Manual Revisão Bibliográfica Sistemática Integrativa: a pesquisa baseada em evidências. Belo Horizonte: Grupo Anima Educação.

Harzing, A. W. 2007. Publish or Perish.

Lievore, P.; Simões, D. R. S.; Silva, K. M.; Drunkler, N. L.; Barana, A. C.; Nogueira, A.; Demiate, I. M. 2015. Chemical characterisation and application of acid whey in fermented milk. Journal of Food Science and Technology, 52: 2083-2092. Doi: 10.1007/s13197-013-1244-z.

Lima, M. V.; Vieira, H. D.; Martins, M. L. L.; Pereira, S. M. F. 2008. Preparo do café despolpado, cereja descascado e natural na região sudoeste da Bahia. Revista Ceres, 55: 124-130.

Martinez-Saez, N.; Ullate, M.; Martin-Cabrejas, M. A.; Martorell, P.; Genovés, S.; Ramon, D.; Castillo del, M. D. 2014. A novel antioxidant beverage for body weight control based on coffee silverskin. Food Chemistry, 150: 227-234. Doi: http://dx.doi.org/10.1016/j. foodchem.2013.10.100.

Minim, V. Análise sensorial: Estudo com consumidores. 2006. Viçosa, MG: Universidade Federal de Viçosa, 3ed.

Oliveira, D. A. L. 2014. Práticas clínicas baseadas em evidências. Especialização em Saúde da Família. Módulo Pedagógico. 53p.

Pereira, A. L.; Bachion, M. M. 2006. Atualidades em revisão sistemática de literatura, critérios de força e grau de recomendação de evidência. Revista Gaúcha de Enfermagem, 27:491.
Polit, D. F.; Beck, C. T. 2006. Using research in evidence-based nursing practice. Essentials of nursing research. Methods, appraisal and utilization. Philadelphia (USA): Lippincott Williams \& Wilkins;. p.457-94.

R Core Team. 2019. R: A language and environment for statistical computing. Vienna: R Foundation for Statistical Computing.

Ribeiro, B. B.; Mendonça, L. M. V. L.; Assis, G. A.; Mendonça, J. M. A.; Malta, M. R.; Montanari, F.F. 2014. Avaliação química e sensorial de blends de Coffea canephora Pierre e Coffea arabica L. Coffee Science, 9: 178-186. Disponível em: offeescience.ufla.br/index.php/Coffeescience/ article/view/596.

Rossini, K.; Anzanello, M. J.; Fogliatto, F. S. 2012. Seleção de atributos em avaliações sensoriais descritivas. Produção, 22: 380-390. Doi: http:// dx.doi.org/10.1590/S0103-65132012005000032.

Silveira, R. C. C. P. 2005. O cuidado de enfermagem e o cateter de Hickman: a busca de evidências [dissertação]. Ribeirão Preto: Universidade de São Paulo, Escola de Enfermagem de Ribeirão Preto, 18: 276-284 2005. Doi: 10.11606/D.22.2005.tde-15082007-153503.

Souza, M.T .; Silva, M. D.; Carvalho, R. 2010. Revisão integrativa: o que é e como fazer. Einstein, 8:102-1066. Doi: http://dx.doi.org/10.1590/ s1679-45082010rw1134.

Stillwell, S. B.; Fineout-Overholt, E.; Melnyk, B. M.; Williamsom, K. M. 2010. Searching for the Evidence: Strategies to help you conduct a successful search. American Journal of Nursing, 110:51-53. Doi: 10.1097/01.NAJ.0000372071.24134.7e.

Teixeira, L. V. Análise Sensorial na Indústria de Alimentos. 2009 Revista da Instituto de Laticínios "Cândido Tostes", 366: 12-21.

Vilela, A.; Monteiro, B.; Correia, E. 2015. Sensory profile of Port wines: categorical principal component analysis, an approach for sensory data treatment. Ciência Técnica e Vitivinícola, 30:1-8. Doi: https://doi. org/10.1051/ctv/20153001001. 
Perfil metodológico de experimentos sensoriais de alimentos de 2014 a 2019

Apêndices

Apêndice 1 - Quadro das características consideradas na avaliação dos 66 artigos selecionados para sugestão de tendências em estudos de análise sensorial, como número de consumidores e/ou provadores treinados, alimentos utilizados, tratamentos, repetições, atributos e teste utilizado.

\begin{tabular}{|c|c|c|c|c|c|c|c|}
\hline ID & Consumidor & $\begin{array}{l}\text { Provador } \\
\text { treinado }\end{array}$ & Alimento & Tratamento & Repetições & Atributos & Teste \\
\hline 1 & 50 & & Tomate & 2 & 2 & Cor e aroma & $\begin{array}{l}\text { Hedônica de } 7 \text { pon- } \\
\text { tos }\end{array}$ \\
\hline 2 & 77 & 13 & $\begin{array}{l}\text { Leite fermentado com } \\
\text { adição de whey }\end{array}$ & 1 & 4 & $\begin{array}{l}\text { Sabor, aroma, cor e } \\
\text { textura; Aceitação }\end{array}$ & $\begin{array}{l}\text { Hedônica de } 9 \text { pon- } \\
\text { tos; Intenção de } \\
\text { compra }\end{array}$ \\
\hline 3 & 32 & & Cookie e pão de forma & 1 & 1 & Aceitação & $\begin{array}{l}\text { Hedônica de } 9 \text { pon- } \\
\text { tos }\end{array}$ \\
\hline 4 & 50 & & Tomate cereja & 1 & 1 & $\begin{array}{l}\text { Sabor, cor, aroma, } \\
\text { aspecto geral }\end{array}$ & $\begin{array}{l}\text { Hedônica de } 9 \text { pon- } \\
\text { tos }\end{array}$ \\
\hline 5 & 51 & & Cereais matinais & 1 & 1 & Aceitação & $\begin{array}{l}\text { Hedônica de } 9 \text { pon- } \\
\text { tos }\end{array}$ \\
\hline 6 & 60 & 17 & Queijo Minas & 1 & 2 & $\begin{array}{l}\text { Sabor e textura; } \\
\text { Aceitação }\end{array}$ & $\begin{array}{l}\text { Hedônica de } 9 \text { pon- } \\
\text { tos; Dominaçãa tem- } \\
\text { poral das sensações }\end{array}$ \\
\hline 7 & & 3 & Blend de cafés & 8 & 3 & Escala de atributos & Escala de atributos \\
\hline 8 & & 22 & Morango & 2 & 3 & $\begin{array}{l}\text { Doçura, sabor, aci- } \\
\text { dez, aroma e textura }\end{array}$ & $\begin{array}{l}\text { Escala estruturada } \\
\text { de } 10 \mathrm{~cm}\end{array}$ \\
\hline 9 & 50 & & Bolo & 5 & 1 & $\begin{array}{l}\text { Sabor, aroma, cor e } \\
\text { textura }\end{array}$ & $\begin{array}{l}\text { Hedônica de } 7 \text { pon- } \\
\text { tos }\end{array}$ \\
\hline 10 & 43 & & Banana & 3 & 1 & Aceitação & $\begin{array}{l}\text { Hedônica de } 9 \text { pon- } \\
\text { tos; Intenção de } \\
\text { compra }\end{array}$ \\
\hline 11 & 35 & & Alface roxa & 1 & 1 & $\begin{array}{l}\text { Teste de comparação } \\
\text { múltipla; Aceitação }\end{array}$ & $\begin{array}{l}\text { Escala estruturada } \\
\text { de } 9 \mathrm{~cm} \text {; Hedônica } \\
\text { de } 9 \text { pontos }\end{array}$ \\
\hline 12 & 40 & & Doce de leite & 3 & 1 & $\begin{array}{l}\text { Sabor, textura, } \\
\text { aspecto geral; Acei- } \\
\text { tação }\end{array}$ & $\begin{array}{l}\text { Hedônica de } 9 \text { pon- } \\
\text { tos }\end{array}$ \\
\hline 13 & 50 & & $\begin{array}{l}\text { Caldo de cana acidifi- } \\
\text { cado }\end{array}$ & 3 & 6 & $\begin{array}{l}\text { Aparência, sabor, } \\
\text { aroma, aspecto geral }\end{array}$ & $\begin{array}{l}\text { Hedônica de } 7 \text { pon- } \\
\text { tos }\end{array}$ \\
\hline 14 & 60 & & Barras de cereais & 2 & 1 & $\begin{array}{c}\text { Aparência, sabor, } \\
\text { aroma, textura, do- } \\
\text { çura e aspecto geral; } \\
\text { Aceitação; Intenção } \\
\text { de compra }\end{array}$ & $\begin{array}{l}\text { Hedônica de } 9 \text { pon- } \\
\text { tos; Intenção de } \\
\text { compra; Frequência } \\
\text { de consumo }\end{array}$ \\
\hline 15 & 48 & & Biscoitos & 4 & 1 & $\begin{array}{l}\text { Aceitação; Intenção } \\
\text { de compra }\end{array}$ & $\begin{array}{l}\text { Hedônica de } 7 \text { pon- } \\
\text { tos; Intenção de } \\
\text { compra }\end{array}$ \\
\hline 16 & & 1 & Café & 3 & 3 & $\begin{array}{l}\text { 'Prova de xícara'; } \\
\text { Acidez sensorial }\end{array}$ & $\begin{array}{l}\text { Escala de valores na } \\
\text { prova de xícara }\end{array}$ \\
\hline 17 & 40 & & $\begin{array}{l}\text { Massas com proteína de } \\
\text { peixe }\end{array}$ & 4 & 1 & $\begin{array}{l}\text { Aparência, sabor, } \\
\text { aroma, textura e } \\
\text { aspecto geral; Acei- } \\
\text { tação; Intenção de } \\
\text { compra }\end{array}$ & $\begin{array}{l}\text { Hedônica de } 9 \text { pon- } \\
\text { tos; Intenção de } \\
\text { compra }\end{array}$ \\
\hline 18 & 32 & & Vinho & 2 & 1 & Aceitação & $\begin{array}{l}\text { Hedônica de } 5 \text { pon- } \\
\text { tos }\end{array}$ \\
\hline 19 & & 12 & Vinho & 3 & 3 & $\begin{array}{l}\text { Aparência, sabor, } \\
\text { aroma, sensação na } \\
\text { boca }\end{array}$ & $\begin{array}{l}\text { Escala de intensi- } \\
\text { dade }\end{array}$ \\
\hline
\end{tabular}

Continua. 
Camocardi, A. F.; Ferreira, E. B.

\begin{tabular}{|c|c|c|c|c|c|c|c|}
\hline ID & Consumidor & $\begin{array}{l}\text { Provador } \\
\text { treinado }\end{array}$ & Alimento & Tratamento & Repetições & Atributos & Teste \\
\hline 20 & & 10 & Carne suína & 4 & 5 & $\begin{array}{l}\text { Aparência, sabor, } \\
\text { aroma, textura }\end{array}$ & $\begin{array}{c}\text { Escala não } \\
\text { estruturada de } 10 \mathrm{~cm}\end{array}$ \\
\hline 21 & 28 & & $\begin{array}{l}\text { Iogurte com óleo } \\
\text { essencial de canela }\end{array}$ & 8 & 1 & Aceitação & $\begin{array}{c}\text { Hedônica de } 9 \\
\text { pontos }\end{array}$ \\
\hline 22 & 50 & & $\begin{array}{l}\text { Abacaxi com óleo } \\
\text { essencial de hortelã }\end{array}$ & 2 & 1 & Aceitação & $\begin{array}{l}\text { Hedônica de } 9 \\
\text { pontos }\end{array}$ \\
\hline 23 & 60 & & Snack de farinha de uva & 3 & 1 & $\begin{array}{l}\text { Cor, aroma, sabor, } \\
\text { textura e aspecto } \\
\text { global }\end{array}$ & $\begin{array}{l}\text { Hedônica de } 9 \\
\text { pontos }\end{array}$ \\
\hline 24 & 60 & & $\begin{array}{l}\text { Nuggets com fibra de } \\
\text { ervilha }\end{array}$ & 3 & 2 & $\begin{array}{l}\text { Aparência, cor, } \\
\text { aroma, sabor, textura } \\
\text { e aspecto global }\end{array}$ & $\begin{array}{l}\text { Hedônica de } 9 \\
\text { pontos }\end{array}$ \\
\hline 25 & 30 & & $\begin{array}{l}\text { Bolo com semente de } \\
\text { abóbora }\end{array}$ & 1 & 1 & $\begin{array}{l}\text { Aparência, cor, } \\
\text { aroma, sabor, textura } \\
\text { e aspecto global }\end{array}$ & $\begin{array}{l}\text { Hedônica de } 9 \\
\text { pontos }\end{array}$ \\
\hline 26 & 110 & & $\begin{array}{l}\text { Cerveja artesanal com } \\
\text { acerola e abacaxi }\end{array}$ & 3 & 1 & $\begin{array}{l}\text { Cor, aroma, sabor, } \\
\text { corpo e aspecto } \\
\text { global; Intenção de } \\
\text { compra }\end{array}$ & $\begin{array}{c}\text { Hedônica de } 9 \\
\text { pontos; Intenção de } \\
\text { compra }\end{array}$ \\
\hline 27 & 33 & & Filé de Pintado & 3 & 1 & $\begin{array}{l}\text { Sabor, aroma, sabor } \\
\text { de 'barro' }\end{array}$ & $\begin{array}{l}\text { Teste de qualidade } \\
\text { para peixes }\end{array}$ \\
\hline 28 & 50 & & $\begin{array}{l}\text { Biscoitos com farinha de } \\
\text { quinoa }\end{array}$ & 3 & 1 & $\begin{array}{l}\text { Aparência, cor, } \\
\text { aroma, sabor, } \\
\text { textura; Intenção de } \\
\text { compra }\end{array}$ & $\begin{array}{c}\text { Hedônica de } 9 \\
\text { pontos; Intenção de } \\
\text { compra }\end{array}$ \\
\hline 29 & & 8 & Carne de ovino & 4 & 3 & $\begin{array}{l}\text { Dureza, suculência, } \\
\text { aroma, sabor e } \\
\text { aspecto global }\end{array}$ & $\begin{array}{l}\text { Escala semi- } \\
\text { estruturada de } 9 \mathrm{~cm}\end{array}$ \\
\hline 30 & 20 & & Café com antioxidante & 4 & 1 & $\begin{array}{l}\text { Cor, odor, sabor e } \\
\text { aspecto geral }\end{array}$ & $\begin{array}{l}\text { Hedônica de } 9 \\
\text { pontos }\end{array}$ \\
\hline 31 & & 10 & Vinho & 6 & 1 & $\begin{array}{c}\text { Escala de atributos e } \\
\text { diagrama de teias de } \\
\text { aranha }\end{array}$ & $\begin{array}{l}\text { Escala estruturada } \\
\text { de } 10 \mathrm{~cm} \text {; Hedônica } \\
\text { de } 9,18 \text { e } 27 \text { pontos }\end{array}$ \\
\hline 32 & 206 & & $\begin{array}{l}\text { Adição de chia em pão } \\
\text { e bolo }\end{array}$ & 2 & 1 & $\begin{array}{l}\text { Aparência, cor, } \\
\text { aroma, sabor, textura } \\
\text { e aspecto global; } \\
\text { Intenção de compra }\end{array}$ & $\begin{array}{c}\text { Hedônica de } 9 \\
\text { pontos; Intenção de } \\
\text { compra }\end{array}$ \\
\hline 33 & & 20 & $\begin{array}{l}\text { Hambúrguer suíno com } \\
\text { fibra de maracujá }\end{array}$ & 3 & 3 & $\begin{array}{l}\text { Escala de atributos; } \\
\text { Aceitação }\end{array}$ & $\begin{array}{l}\text { Hedônica de } 7 \\
\text { pontos }\end{array}$ \\
\hline 34 & & 12 & $\begin{array}{c}\text { Pão de amaranto e } \\
\text { quinoa }\end{array}$ & 7 & 3 & $\begin{array}{l}\text { Escala de atributos; } \\
\text { Análise de } \\
\text { intensidade de } \\
\text { tempo de alimentos } \\
\text { e gostos }\end{array}$ & $\begin{array}{l}\text { Escala estruturada } \\
\text { de } 9 \mathrm{~cm}\end{array}$ \\
\hline 35 & & 25 & Carne bovina modificada & 6 & 1 & $\begin{array}{l}\text { Escala de atributos; } \\
\text { Aceitação }\end{array}$ & $\begin{array}{l}\text { Hedônica de } 5 \\
\text { pontos }\end{array}$ \\
\hline 36 & 22 & & Sopa de tarhana & 5 & 1 & $\begin{array}{l}\text { Cor, sabor, aroma, } \\
\text { sensação na boca e } \\
\text { aspecto global }\end{array}$ & $\begin{array}{l}\text { Hedônica de } 9 \\
\text { pontos }\end{array}$ \\
\hline 37 & & 10 & Lacón curado & 4 & 2 & $\begin{array}{c}\text { Escala de atributos e } \\
\text { diagrama de teias de } \\
\text { aranha }\end{array}$ & $\begin{array}{l}\text { Escala não- } \\
\text { estruturada de } 9 \mathrm{~cm}\end{array}$ \\
\hline 38 & 123 & & Sorvete de chocolate & 6 & 2 & $\begin{array}{c}\text { Aceitação; Seleção } \\
\text { de atributos } \\
\text { favoráveis e } \\
\text { desfavoráveis }\end{array}$ & $\begin{array}{c}\text { Hedônica de } 9 \\
\text { pontos; Perfil pivô }\end{array}$ \\
\hline
\end{tabular}


Perfil metodológico de experimentos sensoriais de alimentos de 2014 a 2019

\begin{tabular}{|c|c|c|c|c|c|c|c|}
\hline ID & Consumidor & $\begin{array}{l}\text { Provador } \\
\text { treinado }\end{array}$ & Alimento & Tratamento & Repetições & Atributos & Teste \\
\hline 39 & & 4 & Café & 6 & 2 & $\begin{array}{c}\text { Aroma, sabor, acidez, } \\
\text { corpo, balanço, sabor } \\
\text { residual; Protocolo } \\
\text { de qualidade para } \\
\text { café }\end{array}$ & $\begin{array}{l}\text { Escala estruturada de } \\
10 \mathrm{~cm}\end{array}$ \\
\hline 40 & & 15 & $\begin{array}{l}\text { Espaguete com farinha } \\
\text { de ervilha }\end{array}$ & 3 & 2 & $\begin{array}{l}\text { Escala de atributos; } \\
\text { Aceitação }\end{array}$ & $\begin{array}{c}\text { Hedônica de } 9 \\
\text { pontos }\end{array}$ \\
\hline 41 & & 20 & $\begin{array}{l}\text { Isotônico de limão e } \\
\text { morango }\end{array}$ & 4 & 3 & $\begin{array}{l}\text { Escala de atributos; } \\
\text { Aceitação }\end{array}$ & $\begin{array}{l}\text { Hedônica de } 5 \\
\text { pontos }\end{array}$ \\
\hline 42 & & 10 & Azeite de oliva & 3 & 1 & $\begin{array}{l}\text { Escala de atributos; } \\
\text { Avaliação de defeitos } \\
\text { e aceitação }\end{array}$ & $\begin{array}{l}\text { Escala não } \\
\text { estruturada de } 10 \mathrm{~cm}\end{array}$ \\
\hline 43 & & 10 & Cookie & 7 & 1 & Aceitação & $\begin{array}{l}\text { Hedônica de } 9 \\
\text { pontos }\end{array}$ \\
\hline 44 & & 6 & Rabanete & 4 & 1 & $\begin{array}{l}\text { Qualidade visual e } \\
\text { olfativa; Intenção de } \\
\text { compra }\end{array}$ & $\begin{array}{l}\text { Hedônica de } 9 \\
\text { pontos; Intenção de } \\
\text { compra; Escala de } \\
\text { odor }\end{array}$ \\
\hline 45 & & 12 & Macarrão sem glúten & 7 & 1 & $\begin{array}{l}\text { Escala de atributos; } \\
\text { Aceitação }\end{array}$ & $\begin{array}{l}\text { Escala estruturada } \\
\text { de } 9 \mathrm{~cm}\end{array}$ \\
\hline 46 & & 10 & Anchovas marinadas & 5 & 6 & $\begin{array}{l}\text { Aparência, sabor, } \\
\text { aroma, aspecto geral }\end{array}$ & $\begin{array}{l}\text { Hedônica de } 9 \\
\text { pontos }\end{array}$ \\
\hline 47 & 88 & & Chouriço de vinho & 6 & 2 & Intenção de compra & Intenção de consumo \\
\hline 48 & 60 & & Batata frita & 3 & 1 & $\begin{array}{l}\text { Aparência, cor, } \\
\text { aroma, sabor, textura } \\
\text { e aspecto global }\end{array}$ & $\begin{array}{c}\text { Hedônica de } 3 \\
\text { pontos }\end{array}$ \\
\hline 49 & & 9 & Presunto curado & 2 & 4 & Escala de atributos & $\begin{array}{c}\text { Escala não } \\
\text { estruturada de } 10 \mathrm{~cm}\end{array}$ \\
\hline 50 & & 30 & Salsicha turca curada & 4 & 3 & $\begin{array}{c}\text { Escala de atributos e } \\
\text { diagrama de teias de } \\
\text { aranha }\end{array}$ & $\begin{array}{l}\text { Hedônica de } 7 \\
\text { pontos }\end{array}$ \\
\hline 51 & & 10 & Vinho & 4 & 2 & $\begin{array}{l}\text { Escala de atributos e } \\
\text { diagrama de teias de } \\
\text { aranha; Aceitação }\end{array}$ & $\begin{array}{c}\text { Escala não } \\
\text { estruturada de } 10 \mathrm{~cm}\end{array}$ \\
\hline 52 & & 8 & Presunto curado & 2 & 1 & $\begin{array}{c}\text { Escala de atributos e } \\
\text { diagrama de teias de } \\
\text { aranha }\end{array}$ & $\begin{array}{l}\text { Escala estruturada } \\
\text { de } 9 \mathrm{~cm}\end{array}$ \\
\hline 53 & & 6 & Filé de Truta & 4 & 9 & $\begin{array}{l}\text { Aparência, cor, } \\
\text { aroma, sabor, textura } \\
\text { e aspecto global }\end{array}$ & $\begin{array}{l}\text { Hedônica de } 9 \\
\text { pontos }\end{array}$ \\
\hline 54 & 105 & & Iogurte & 11 & 1 & $\begin{array}{l}\text { Cremosidade, aroma, } \\
\text { sabor e aspecto } \\
\text { geral; Aceitação }\end{array}$ & $\begin{array}{c}\text { Hedônica de } 9 \\
\text { pontos }\end{array}$ \\
\hline 55 & 103 & & Bebida nutritiva de sorgo & 2 & 1 & $\begin{array}{l}\text { Cor, aroma, sabor, } \\
\text { textura e aspecto } \\
\text { global; Intenção de } \\
\text { compra }\end{array}$ & $\begin{array}{l}\text { Hedônica de } 10 \\
\text { pontos; Intenção de } \\
\text { compra }\end{array}$ \\
\hline 56 & 51 & & Pão enriquecido & 4 & 1 & Aceitação & $\begin{array}{c}\text { Hedônica de } 9 \\
\text { pontos; Intenção de } \\
\text { compra }\end{array}$ \\
\hline 57 & & 10 & Vinho & 4 & 2 & $\begin{array}{c}\text { Escala de atributos e } \\
\text { diagrama de teias de } \\
\text { aranha }\end{array}$ & $\begin{array}{c}\text { Escala não } \\
\text { estruturada de } 10 \mathrm{~cm}\end{array}$ \\
\hline 58 & & 9 & $\begin{array}{l}\text { Peito de frango com } \\
\text { revestimento }\end{array}$ & 2 & 3 & $\begin{array}{l}\text { Escala de atributos; } \\
\text { Aceitação }\end{array}$ & $\begin{array}{l}\text { Escala de atributos; } \\
\text { Escala de } 3 \text { pontos }\end{array}$ \\
\hline
\end{tabular}


Camocardi, A. F.; Ferreira, E. B.

\begin{tabular}{|c|c|c|c|c|c|c|c|}
\hline ID & Consumidor & $\begin{array}{l}\text { Provador } \\
\text { treinado }\end{array}$ & Alimento & Tratamento & Repetições & Atributos & Teste \\
\hline 59 & & 10 & Biscoitos & 4 & 1 & $\begin{array}{l}\text { Cor, aroma, sabor, } \\
\text { crocância, textura e } \\
\text { aspecto global }\end{array}$ & $\begin{array}{l}\text { Hedônica de } 9 \\
\text { pontos }\end{array}$ \\
\hline 60 & & 10 & $\begin{array}{l}\text { Carne moída preservado } \\
\text { por óleos essenciais }\end{array}$ & 6 & 2 & $\begin{array}{l}\text { Aroma e sabor; } \\
\text { Aceitação }\end{array}$ & $\begin{array}{l}\text { Hedônica de } 9 \\
\text { pontos }\end{array}$ \\
\hline 61 & 26 & & $\begin{array}{l}\text { Biscoitos com borra de } \\
\text { café }\end{array}$ & 8 & 1 & $\begin{array}{l}\text { Cor, sabor, textura e } \\
\text { aspecto global }\end{array}$ & $\begin{array}{l}\text { Hedônica de } 7 \\
\text { pontos }\end{array}$ \\
\hline 62 & & 13 & Vinho & 4 & 1 & $\begin{array}{c}\text { Escala de atributos e } \\
\text { diagrama de teias de } \\
\text { aranha }\end{array}$ & $\begin{array}{l}\text { Hedônica de } 10 \\
\text { pontos }\end{array}$ \\
\hline 63 & & 5 & $\begin{array}{c}\text { Alimentos à base de } \\
\text { aveia }\end{array}$ & 4 & 1 & $\begin{array}{c}\text { Escala de atributos e } \\
\text { diagrama de teias de } \\
\text { aranha }\end{array}$ & $\begin{array}{l}\text { Hedônica de } 5 \\
\text { pontos }\end{array}$ \\
\hline 64 & 63 & & Carne depurada & 6 & 1 & Aceitação & $\begin{array}{c}\text { Hedônica de } 9 \\
\text { pontos }\end{array}$ \\
\hline 65 & 150 & & $\begin{array}{l}\text { Hambúrguer com } \\
\text { reaproveitamento de } \\
\text { alimentos }\end{array}$ & 5 & 1 & $\begin{array}{l}\text { Aceitação; Intenção } \\
\text { de compra }\end{array}$ & $\begin{array}{c}\text { Hedônica de } 9 \\
\text { pontos; Intenção de } \\
\text { compra }\end{array}$ \\
\hline 66 & 96 & & $\begin{array}{l}\text { Barra de cereais sem } \\
\text { glúten }\end{array}$ & 4 & 2 & Aceitação & $\begin{array}{l}\text { Hedônica de } 10 \\
\text { pontos }\end{array}$ \\
\hline
\end{tabular}


Perfil metodológico de experimentos sensoriais de alimentos de 2014 a 2019

Apêndice 2 - Quadro das referências dos artigos selecionados entre os anos de 2014 à 2019, considerando número de citações de acordo com o idioma, contendo a fonte da publicação e link de acesso.

\begin{tabular}{|c|c|c|c|c|c|c|}
\hline ID & Título & Ano & Publicado em & $\begin{array}{l}\text { Cita- } \\
\text { ções }\end{array}$ & Idioma & Link de acesso \\
\hline 1 & $\begin{array}{l}\text { Organic versus conventional tomatoes: Influ- } \\
\text { ence on physicochemical parameters, bioactive } \\
\text { compounds and sensorial attributes }\end{array}$ & 2014 & $\begin{array}{l}\text { Food and Chemical } \\
\text { Toxicology }\end{array}$ & 50 & Inglês & https://wow.link/bXt \\
\hline 2 & $\begin{array}{l}\text { Chemical characterisation and application of } \\
\text { acid whey in fermented milk }\end{array}$ & 2015 & $\begin{array}{l}\text { Journal of Food Science } \\
\text { and Technology }\end{array}$ & 28 & Inglês & https://wow.link/nXt \\
\hline 3 & $\begin{array}{l}\text { Efeito da adição de amaranto na composição e } \\
\text { na aceitabilidade do biscoito tipo cookie e do } \\
\text { pão de forma }\end{array}$ & 2014 & $\begin{array}{l}\text { Alimentos e Nutrição } \\
\text { Araraquara }\end{array}$ & 25 & $\begin{array}{l}\text { Portu- } \\
\text { guês }\end{array}$ & https://wow.link/mXt \\
\hline 4 & $\begin{array}{l}\text { Análise sensorial e físico-química de frutos } \\
\text { tomate cereja orgânicos }\end{array}$ & 2014 & Revista Caatinga & 23 & $\begin{array}{l}\text { Portu- } \\
\text { guês }\end{array}$ & https://wow.link/JXt \\
\hline 5 & $\begin{array}{l}\text { Comparing sorghum and wheat whole grain } \\
\text { breakfast cereals: Sensorial acceptance and } \\
\text { bioactive compound content }\end{array}$ & 2017 & Food Chemistry & 23 & Inglês & https://wow.link/LXt \\
\hline 6 & $\begin{array}{l}\text { Temporal dominance of sensations sensory } \\
\text { profile and drivers of liking of artisanal Minas } \\
\text { cheese produced in the region of Serra da Ca- } \\
\text { nastra, Brazil }\end{array}$ & 2016 & Journal of Dairy Science & 19 & Inglês & https://wow.link/CXt \\
\hline 7 & $\begin{array}{l}\text { Avaliação química e sensorial de blends de } \\
\text { Coffea canephora Pierre e Coffea arabica L. }\end{array}$ & 2014 & SBICafé & 17 & $\begin{array}{l}\text { Portu- } \\
\text { guês }\end{array}$ & https://wow.link/BXt \\
\hline 8 & $\begin{array}{l}\text { Postharvest quality of strawberry produced } \\
\text { during two consecutive seasons }\end{array}$ & 2014 & Horticultura Brasileira & 17 & Inglês & https://wow.link/MXt \\
\hline 9 & $\begin{array}{l}\text { Effect of substituting of cocoa powder for carob } \\
\text { flour in cakes made with soy and banana flours }\end{array}$ & 2015 & $\begin{array}{l}\text { International Food Re- } \\
\text { search Journal }\end{array}$ & 17 & Inglês & https://wow.link/1Ct \\
\hline 10 & $\begin{array}{l}\text { Caracterização pós-colheita e sensorial de ge- } \\
\text { nótipos de bananeiras tipo prata }\end{array}$ & 2015 & $\begin{array}{l}\text { Revista Brasileira de } \\
\text { Fruticultura }\end{array}$ & 16 & $\begin{array}{l}\text { Portu- } \\
\text { guês }\end{array}$ & https://wow.link/3Ct \\
\hline 11 & $\begin{array}{l}\text { Ultrasound improves antimicrobial effect of } \\
\text { sodium dichloroisocyanurate to reduce Salmo- } \\
\text { nella Typhimurium on purple cabbage }\end{array}$ & 2018 & $\begin{array}{l}\text { International Journal of } \\
\text { Food Microbiology }\end{array}$ & 16 & Inglês & https://wow.link/4Ct \\
\hline 12 & $\begin{array}{l}\text { Análise físico-química e sensorial de doce de } \\
\text { leite produzido sem adição de sacarose }\end{array}$ & 2015 & Revista Ceres & 15 & $\begin{array}{l}\text { Portu- } \\
\text { guês }\end{array}$ & https://wow.link/6Ct \\
\hline 13 & $\begin{array}{l}\text { Effect of pasteurization temperature on stabili- } \\
\text { ty of an acidified sugarcane juice beverage }\end{array}$ & 2014 & $\begin{array}{l}\text { Ciência e Agrotecno- } \\
\text { logia }\end{array}$ & 15 & Inglês & https://wow.link/9Ct \\
\hline 14 & $\begin{array}{l}\text { Preparation of a cereal bar containing bocaiu- } \\
\text { va: physical, nutritional, microbiological and } \\
\text { sensory evaluation }\end{array}$ & 2014 & Acta Scientiarum & 15 & Inglês & https://wow.link/wCt \\
\hline 15 & $\begin{array}{l}\text { Elaboração e avaliação de biscoitos sem glúten } \\
\text { a partir de farelo de arroz e farinhas de arroz } \\
\text { e de soja }\end{array}$ & 2015 & $\begin{array}{l}\text { Brazilian Journal of } \\
\text { Food Technology }\end{array}$ & 14 & $\begin{array}{l}\text { Portu- } \\
\text { guês }\end{array}$ & https://wow.link/rCt \\
\hline 16 & $\begin{array}{l}\text { Preparo do café despolpado, cereja descascado } \\
\text { e natural na região sudoeste da Bahia }\end{array}$ & 2015 & Revista Ceres & 14 & $\begin{array}{l}\text { Portu- } \\
\text { guês }\end{array}$ & https://wow.link/uCt \\
\hline 17 & $\begin{array}{l}\text { Fresh pasta enrichment with protein concen- } \\
\text { trate of tilapia: nutritional and sensory char- } \\
\text { acteristics }\end{array}$ & 2016 & $\begin{array}{l}\text { Food Science and Tech- } \\
\text { nology }\end{array}$ & 14 & Inglês & https://wow.link/pCt \\
\hline 18 & $\begin{array}{l}\text { Thermovinification of grapes from the Caber- } \\
\text { net Sauvignon and Pinot Noir varieties using } \\
\text { immobilized yeasts }\end{array}$ & 2014 & $\begin{array}{l}\text { European Food Re- } \\
\text { search and Technology }\end{array}$ & 14 & Inglês & https://wow.link/aCt \\
\hline 19 & $\begin{array}{l}\text { Sensory profile of Port wines: categorical } \\
\text { principal component analysis, an approach for } \\
\text { sensory data treatment }\end{array}$ & 2015 & $\begin{array}{l}\text { Ciência e Técnica Viti- } \\
\text { vinícola }\end{array}$ & 13 & Inglês & https://wow.link/sCt \\
\hline 20 & $\begin{array}{l}\text { Effect of Breed and Sex on Pork Meat Sensory } \\
\text { Evaluation }\end{array}$ & 2014 & $\begin{array}{l}\text { Food and Nutrition } \\
\text { Sciences }\end{array}$ & 13 & Inglês & https://wow.link/dCt \\
\hline
\end{tabular}


Camocardi, A. F; Ferreira, E. B.

\begin{tabular}{|c|c|c|c|c|c|c|}
\hline ID & Título & Ano & Publicado em & $\begin{array}{l}\text { Cita- } \\
\text { ções }\end{array}$ & Idioma & Link de acesso \\
\hline 21 & $\begin{array}{l}\text { Assessment of antimicrobial activity of cinna- } \\
\text { mon (Cinnamomum zeylanicum) essential oil } \\
\text { combined with EDTA and polyethylene glycol } \\
\text { in yogurt }\end{array}$ & 2015 & Acta Scientiarum & 12 & Inglês & https://wow.link/fCt \\
\hline 22 & $\begin{array}{l}\text { Antimicrobial and aromatic edible coating on } \\
\text { fresh-cut pineapple preservation }\end{array}$ & 2014 & Ciência Rural & 12 & Inglês & https://wow.link/gCt \\
\hline 23 & $\begin{array}{l}\text { Obtenção e caracterização de farinha de casca } \\
\text { de uva e sua utilização em snack extrusado }\end{array}$ & 2016 & $\begin{array}{l}\text { Brazilian Journal of } \\
\text { Food Technology }\end{array}$ & 11 & $\begin{array}{l}\text { Portu- } \\
\text { guês }\end{array}$ & https://wow.link/hCt \\
\hline 24 & $\begin{array}{l}\text { Development and evaluation of chicken nug- } \\
\text { gets with partial replacement of meat and fat } \\
\text { by pea fibre }\end{array}$ & 2015 & $\begin{array}{l}\text { Brazilian Journal of } \\
\text { Food Technology }\end{array}$ & 11 & Inglês & https://wow.link/jCt \\
\hline 25 & $\begin{array}{l}\text { Elaboração de bolos enriquecidos com semente } \\
\text { de abóbora: avaliaçãa química, física e senso- } \\
\text { rial }\end{array}$ & 2014 & $\begin{array}{l}\text { Boletim Centro de Pes- } \\
\text { quisa de Processamento } \\
\text { de Alimentos }\end{array}$ & 10 & $\begin{array}{l}\text { Portu- } \\
\text { guês }\end{array}$ & https://wow.link/kCt \\
\hline 26 & $\begin{array}{l}\text { Desenvolvimento de Cerveja Artesanal com } \\
\text { Acerola (Malpighia emarginata DC) e Abacaxi } \\
\text { (Ananas comosus L. Merril) }\end{array}$ & 2015 & $\begin{array}{l}\text { Revista Verde de Agro- } \\
\text { ecologia e Desenvolvi- } \\
\text { mento Sustentável }\end{array}$ & 10 & $\begin{array}{l}\text { Portu- } \\
\text { guês }\end{array}$ & https://wow.link/zCt \\
\hline 27 & $\begin{array}{l}\text { Influência da densidade de estocagem e dos } \\
\text { sistemas de criação intensivo e semi-intensivo } \\
\text { no rendimento de carcaça, na qualidade nutri- } \\
\text { cional do filé e nas características organolépti- } \\
\text { cas do pintado Pseudoplatystoma corruscans }\end{array}$ & 2018 & $\begin{array}{l}\text { Boletim do Instituto da } \\
\text { Pesca }\end{array}$ & 10 & $\begin{array}{l}\text { Portu- } \\
\text { guês }\end{array}$ & https://wow.link/xCt \\
\hline 28 & $\begin{array}{l}\text { Biscoitos com diferentes concentrações de fari- } \\
\text { nha de quinoa em substituição parcial à farinha } \\
\text { de trigo }\end{array}$ & 2014 & $\begin{array}{l}\text { Brazilian Journal of } \\
\text { Food Technology }\end{array}$ & 10 & $\begin{array}{l}\text { Portu- } \\
\text { guês }\end{array}$ & https://wow.link/cCt \\
\hline 29 & $\begin{array}{l}\text { Qualidade da carne de ovinos de diferentes } \\
\text { raças de reprodutores terminados sob dois sis- } \\
\text { temas de produção }\end{array}$ & 2014 & $\begin{array}{l}\text { Revista Brasileira de } \\
\text { Saúde e Produção Ani- } \\
\text { mal }\end{array}$ & 10 & $\begin{array}{l}\text { Portu- } \\
\text { guês }\end{array}$ & https://wow.link/bCt \\
\hline 30 & $\begin{array}{l}\text { A novel antioxidant beverage for body weight } \\
\text { control based on coffee silverskin }\end{array}$ & 2014 & Food Chemistry & 53 & Inglês & https://wow.link/nCt \\
\hline 31 & $\begin{array}{l}\text { Volatile compounds and sensorial characterisa- } \\
\text { tion of red wine aged in cherry, chestnut, false } \\
\text { acacia, ash and oak wood barrels }\end{array}$ & 2014 & Food Chemistry & 50 & Inglês & shorturl.at/gKX13 \\
\hline 32 & $\begin{array}{l}\text { Addition of chia seed mucilage for reduction of } \\
\text { fat content in bread and cakes }\end{array}$ & 2017 & Food Chemistry & 50 & Inglês & shorturl.at/hpZ07 \\
\hline 33 & $\begin{array}{l}\text { Quality characteristics of pork burger added } \\
\text { with albedo-fiber powder obtained from yellow } \\
\text { passion fruit (Passiflora edulis var. flavicarpa) } \\
\text { co-products }\end{array}$ & 2014 & Meat Science & 49 & Inglês & shorturl.at/suGXY \\
\hline 34 & $\begin{array}{l}\text { Addition of quinoa and amaranth flour in glu- } \\
\text { ten-free breads: Temporal profile and instru- } \\
\text { mental analysis }\end{array}$ & 2015 & $\begin{array}{l}\text { Food Science and Tech- } \\
\text { nology }\end{array}$ & 49 & Inglês & shorturl.at/DFUVX \\
\hline 35 & $\begin{array}{l}\text { Development of reduced fat minced meats } \\
\text { using inulin and bovine plasma proteins as fat } \\
\text { replacers }\end{array}$ & 2014 & Meat Science & 48 & Inglês & shorturl.at/nuCL2 \\
\hline 36 & $\begin{array}{l}\text { Phenolic acid composition, antioxidant activity } \\
\text { and phenolic content of tarhana supplemented } \\
\text { with oat flour }\end{array}$ & 2014 & Food Chemistry & 44 & Inglês & shorturl.at/mrs89 \\
\hline 37 & $\begin{array}{l}\text { Influence of partial replacement of } \mathrm{NaCl} \text { with } \\
\mathrm{KCl}, \mathrm{CaCl} 2 \text { and } \mathrm{MgCl} 2 \text { on proteolysis, lipolysis } \\
\text { and sensory properties during the manufacture } \\
\text { of dry-cured lacón }\end{array}$ & 2015 & Food Control & 44 & Inglês & shorturl.at/imnW7 \\
\hline 38 & $\begin{array}{l}\text { Novel and successful free comments method } \\
\text { for sensory characterization of chocolate ice } \\
\text { cream: A comparative study between pivot } \\
\text { profile and comment analysis }\end{array}$ & 2016 & Journal of Dairy Science & 44 & Inglês & shorturl.at/ltIX0 \\
\hline
\end{tabular}


Perfil metodológico de experimentos sensoriais de alimentos de 2014 a 2019

\begin{tabular}{|c|c|c|c|c|c|c|}
\hline ID & Título & Ano & Publicado em & $\begin{array}{l}\text { Cita- } \\
\text { ções }\end{array}$ & Idioma & Link de acesso \\
\hline 39 & $\begin{array}{l}\text { Conducting starter culture-controlled fermen- } \\
\text { tations of coffee beans during on-farm wet } \\
\text { processing: Growth, metabolic analyses and } \\
\text { sensorial effects }\end{array}$ & 2015 & $\begin{array}{l}\text { Food Research Interna- } \\
\text { tional }\end{array}$ & 41 & Inglês & shorturl.at/vyDP9 \\
\hline 40 & $\begin{array}{l}\text { Chemical composition, sensory and cooking } \\
\text { quality evaluation of durum wheat spaghetti } \\
\text { enriched with pea flour }\end{array}$ & 2014 & $\begin{array}{l}\text { International Journal of } \\
\text { Food Science and Tech- } \\
\text { nology }\end{array}$ & 38 & Inglês & shorturl.at/atw34 \\
\hline 41 & $\begin{array}{l}\text { Evaluation of sensorial, phytochemical and bio- } \\
\text { logical properties of new isotonic beverages en- } \\
\text { riched with lemon and berries during shelf life }\end{array}$ & 2014 & $\begin{array}{l}\text { Journal of the Science } \\
\text { of Food and Agriculture }\end{array}$ & 37 & Inglês & shorturl.at/avHPX \\
\hline 42 & $\begin{array}{l}\text { Olive oil sensory defects classification with } \\
\text { data fusion of instrumental techniques and } \\
\text { multivariate analysis (PLS-DA) }\end{array}$ & 2016 & Food Chemistry & 37 & Inglês & shorturl.at/1OP25 \\
\hline 43 & $\begin{array}{l}\text { Effect of flaxseed incorporation on physical, } \\
\text { sensorial, textural and chemical attributes of } \\
\text { cookies }\end{array}$ & 2014 & $\begin{array}{l}\text { International Food Re- } \\
\text { search Journal }\end{array}$ & 37 & Inglês & shorturl.at/dlnOX \\
\hline 44 & $\begin{array}{l}\text { Effect of light exposure on sensorial quality, } \\
\text { concentrations of bioactive compounds and an- } \\
\text { tioxidant capacity of radish microgreens during } \\
\text { low temperature storage }\end{array}$ & 2014 & Food Chemistry & 36 & Inglês & shorturl.at/ehwyK \\
\hline 45 & $\begin{array}{l}\text { Utilization of sorghum, rice, corn flours with } \\
\text { potato starch for the preparation of gluten-free } \\
\text { pasta }\end{array}$ & 2016 & Food Chemistry & 36 & Inglês & shorturl.at/ahmzT \\
\hline 46 & $\begin{array}{l}\text { Effects of olive oil and olive oil-pomegranate } \\
\text { juice sauces on chemical, oxidative and senso- } \\
\text { rial quality of marinated anchovy }\end{array}$ & 2014 & Food Chemistry & 34 & Inglês & shorturl.at/wBHR8 \\
\hline 47 & $\begin{array}{l}\text { Behaviour of food-borne pathogens on dry } \\
\text { cured sausage manufactured with herbs and } \\
\text { spices essential oils and their sensorial accept- } \\
\text { ability }\end{array}$ & 2016 & Food Control & 34 & Inglês & shorturl.at/rvxG6 \\
\hline 48 & $\begin{array}{l}\text { Feasibility of using almond gum as coating } \\
\text { agent to improve the quality of fried potato } \\
\text { chips: Evaluation of sensorial properties }\end{array}$ & 2016 & $\begin{array}{l}\text { Food Science and Tech- } \\
\text { nology }\end{array}$ & 33 & Inglês & shorturl.at/fmAZ0 \\
\hline 49 & $\begin{array}{l}\text { The effect of ripening time on the chemical, } \\
\text { textural, volatile and sensorial traits of Bicep } \\
\text { femoris and Semimembranosus muscles of the } \\
\text { Slovenian dry-cured ham Kraški pršut }\end{array}$ & 2015 & Meat Science & 33 & Inglês & shorturl.at/JLPZ9 \\
\hline 50 & $\begin{array}{l}\text { Effect of autochthonous starter cultures isolat- } \\
\text { ed from Siahmazgi cheese on physicochemical, } \\
\text { microbiological and volatile compound profiles } \\
\text { and sensorial attributes of sucuk, a Turkish } \\
\text { dry-fermented sausage }\end{array}$ & 2014 & Meat Science & 33 & Inglês & shorturl.at/cft05 \\
\hline 51 & $\begin{array}{l}\text { Quality and Composition of Red Wine Fer- } \\
\text { mented with Schizosaccharomyces pombe as } \\
\text { Sole Fermentative Yeast, and in Mixed and } \\
\text { Sequential Fermentations with Saccharomyces } \\
\text { cerevisiae }\end{array}$ & 2014 & $\begin{array}{l}\text { Food Technology and } \\
\text { Biotechnology }\end{array}$ & 33 & Inglês & shorturl.at/lDGH7 \\
\hline 52 & $\begin{array}{l}\text { Physicochemical changes during manufacture } \\
\text { and final sensory characteristics of dry-cured } \\
\text { Celta ham. Effect of muscle type }\end{array}$ & 2014 & Food Control & 33 & Inglês & shorturl.at/pHJT1 \\
\hline 53 & $\begin{array}{l}\text { Effects of Gelatin-Based Edible Films Enriched } \\
\text { with Laurel Essential Oil on the Quality of } \\
\text { Rainbow Trout (Oncorhynchus mykiss) Fillets } \\
\text { During Refrigerated Storage }\end{array}$ & 2014 & $\begin{array}{l}\text { Food Technology and } \\
\text { Biotechnology }\end{array}$ & 33 & Inglês & $\begin{array}{c}\text { https://hrcak.srce. } \\
\text { hr/126179 }\end{array}$ \\
\hline 54 & $\begin{array}{l}\text { Optimization of an organic yogurt based on } \\
\text { sensorial, nutritional, and functional perspec- } \\
\text { tives }\end{array}$ & 2017 & Food Chemistry & 31 & Inglês & shorturl.at/imFHL \\
\hline
\end{tabular}


Camocardi, A. F.; Ferreira, E. B.

\begin{tabular}{|c|c|c|c|c|c|c|}
\hline ID & Título & Ano & Publicado em & $\begin{array}{l}\text { Cita- } \\
\text { ções }\end{array}$ & Idioma & Link de acesso \\
\hline 55 & $\begin{array}{l}\text { A low calorie and nutritive sorghum powdered } \\
\text { drink mix: Influence of tannin on the sensorial } \\
\text { and functional properties }\end{array}$ & 2018 & $\begin{array}{l}\text { Journal of Cereal } \\
\text { Science }\end{array}$ & 13 & Inglês & shorturl.at/fwz58 \\
\hline 56 & $\begin{array}{l}\text { Bread enriched with flour from cinereous cock- } \\
\text { roach (Nauphoeta cinerea) }\end{array}$ & 2017 & $\begin{array}{l}\text { Innovative Food Science } \\
\text { and Emerging Technol- } \\
\text { ogies }\end{array}$ & 12 & Inglês & shorturl.at/imtQ3 \\
\hline 57 & $\begin{array}{l}\text { Dynamic analysis of physiological properties of } \\
\text { Torulaspora delbrueckii in wine fermentations } \\
\text { and its incidence on wine quality }\end{array}$ & 2015 & $\begin{array}{l}\text { Applied microbial and } \\
\text { cell physiology }\end{array}$ & 89 & Inglês & shorturl.at/juzAG \\
\hline 58 & $\begin{array}{l}\text { Effect of nanocomposite packaging containing } \\
\text { different proportions of } \mathrm{ZnO} \text { and } \mathrm{Ag} \text { on chick- } \\
\text { en breast meat quality }\end{array}$ & 2014 & $\begin{array}{l}\text { Journal of Food Engi- } \\
\text { neering }\end{array}$ & 79 & Inglês & shorturl.at/ovIJ1 \\
\hline 59 & $\begin{array}{l}\text { Evaluation of functional properties of compos- } \\
\text { ite flours and sensorial attributes of composite } \\
\text { flour biscuits }\end{array}$ & 2015 & $\begin{array}{l}\text { Journal of Food Science } \\
\text { and Technology }\end{array}$ & 70 & Inglês & shorturl.at/aCDQ8 \\
\hline 60 & $\begin{array}{l}\text { Antimicrobial effect of essential oils in combi- } \\
\text { nations against five bacteria and their effect on } \\
\text { sensorial quality of ground meat }\end{array}$ & 2016 & $\begin{array}{l}\text { Food Science and Tech- } \\
\text { nology }\end{array}$ & 65 & Inglês & shorturl.at/sCJ56 \\
\hline 61 & $\begin{array}{l}\text { Use of spent coffee grounds as food ingredient } \\
\text { in bakery products }\end{array}$ & 2017 & Food Chemistry & 57 & Inglês & shorturl.at/wEGR6 \\
\hline 62 & $\begin{array}{l}\text { Effect on quality and composition of Riesling } \\
\text { wines fermented by sequential inoculation } \\
\text { with non-Saccharomyces and Saccharomyces } \\
\text { cerevisiae }\end{array}$ & 2015 & $\begin{array}{l}\text { European Food Re- } \\
\text { search and Technology }\end{array}$ & 56 & Inglês & shorturl.at/nyzBH \\
\hline 63 & $\begin{array}{l}\text { Lactobacillus plantarum strains for multifunc- } \\
\text { tional oat-based foods }\end{array}$ & 2016 & $\begin{array}{l}\text { Food Science and Tech- } \\
\text { nology }\end{array}$ & 34 & Inglês & shorturl.at/awyS6 \\
\hline 64 & $\begin{array}{l}\text { Características sensoriais e bromatológicas da } \\
\text { carne de Prochilodus lineatus após depuração }\end{array}$ & 2017 & $\begin{array}{l}\text { Revista de Ciências } \\
\text { Agrárias }\end{array}$ & - & $\begin{array}{l}\text { Portu- } \\
\text { guês }\end{array}$ & shorturl.at/iIVX3 \\
\hline 65 & $\begin{array}{l}\text { Desenvolvimento e análise sensorial de dife- } \\
\text { rentes tipos de hambúrgueres funcionais utili- } \\
\text { zando o reaproveitamento de alimentos }\end{array}$ & 2016 & $\begin{array}{l}\text { Revista de Ciências } \\
\text { Agrárias }\end{array}$ & - & $\begin{array}{l}\text { Portu- } \\
\text { guês }\end{array}$ & shorturl.at/eyTY8 \\
\hline 66 & $\begin{array}{l}\text { Acceptability and study of shelf life of gluten } \\
\text { free cereal bar with popped and extruded sor- } \\
\text { ghum based on a consumer acceptability }\end{array}$ & 2018 & $\begin{array}{l}\text { Revista de Ciências } \\
\text { Agrárias }\end{array}$ & - & Inglês & shorturl.at/ioptJ \\
\hline
\end{tabular}

